\title{
YANMIŞ ORMAN ALANLARININ DESTEK VEKTÖR MAKINALARI VE ROTASYON ORMAN İLERİ SINIFLANDIRMA YÖNTEMLERİ KULLANARAK NESNE-TABANLI TESPITI: WORLDVIEW-2 UYDU GÖRÜNTÜSÜ ÖRNEĞİ
}

\author{
Murat KURUCA ${ }^{1}$, Dilek KÜÇÜK $M A T C I^{2}, U \breve{g u r} A V D A N^{3}$ \\ ${ }^{1}$ Yüksek Lisans Öğrencisi, Anadolu Üniversitesi, Yer ve Uzay Bilimleri Enstitüsü, Jeodezi ve Coğrafi Bilgi Teknolojileri Anabilim Dalı, 26555, \\ Tepebaşı, Eskişehir, mkuruca @ anadolu.edu.tr \\ ${ }^{2}$ Öğr.Gör., Anadolu Üniversitesi, Yer ve Uzay Bilimleri Enstitüsü, Jeodezi ve Coğrafi Bilgi Teknolojileri Anabilim Dalı, 26555, Tepebaşı, \\ Eskişehir,dkmatci@anadolu.edu.tr \\ ${ }^{3}$ Doç. Dr., Anadolu Üniversitesi, Yer ve Uzay Bilimleri Enstitüsü, Jeodezi ve Coğrafi Bilgi Teknolojileri Anabilim Dalı, 26555, Tepebaşı, \\ Eskişehir, uavdan@anadolu.edu.tr
}

\begin{abstract}
ÖZET
İnsanoğlunun gerek dikkatsizliği gerekse kasti olarak orman alanlarını tahrip etmesi endişe verici boyuttadır. Türkiye Ormancılar Derneği (TOD) verileri göstermektedir ki toplam 9156 hektar orman alanı 2016 yıl içerisinde yanmıştır. Bu yangınların \%23,5'i, Türkiye'nin birinci derece yangın bölgesi olan Antalya'da meydana gelmiştir [http-1]. Bu çalışmada, Adrasan ve Kumluca (Antalya) bölgelerinde 2016 yll Haziran ayında meydana gelen yangindan etkilenen alanların Worldview-2 uydusuna ait Temmuz 2016 tarihli ve yüksek çözzünürlüklü uydu görüntüsü temin edilmiştir. Uzaktan algılanmış görüntünün bantları önce Erdas 2014 programı ile birleştirilmiş ve füzyon uygulanmıştır. Ardından eCognition yazılımıyla ölçek:120, şekil:0.4, yoğunluk:0.6 parametreleri ve Normalize Edilmiş Farksal Bitki Örtüsü İndisi (NDVI), Küresel Çevre İzleme İndisi (GEMI), Toprak Ayarlı Bitki Örtüsü İndisi (SAVI), Bitki Örtüsü İndisi (VI), Bitki Örtüsü Oran İndisi (RVI), ve Ashburn Bitki İndisi (AVI) indisleri kullanılarak segmentasyon işlemi yapılmıştır. Segmentasyon sonrası elde edilen şekil dosyaları ArcMap programı yardımıyla kesilerek eğitim ve test verisi oluşturulmuştur. Elde edilen bu dosyalar Destek Vektör Makinaları (DVM) ve Rotasyon Orman (ROR) ileri sınıflandırma teknikleri ile Weka programında sınıflandırmaları yapılmıştır. Son olarak da sınıflandırma sonuçlarının doğruluk analizi yapılmıştır. Yapılan analiz sonuçlarına göre ROR için Kappa 0.86 ve Toplam doğruluk 0.93, DVM için ise Kappa 0.9 ve Toplam doğruluk 0.95 bulunmuştur. Sonuçlar karşılaştırlldı̆̆ında DVM'in ROR'a göre daha başarllı bir yöntem olduğu görülmektedir.
\end{abstract}

Anahtar Sözcükler: destek vektör makineleri, nesne-tabanlı sınıflandırma, rotasyon orman, Worldview-2, yanmış orman alanları

\begin{abstract}
Carelessness of mankind and that they intentionally destroy forest areas is at an alarming rate. Foresters' Association of Turkey (TOD) data show that a total of 9156 hectares of forest was burned in 2016. 23,5\% of the blazes occurred in Antalya region [http1]. In this study, high resolution satellite images, belonging to the Worldview-2 satellite, of the areas affected from the blazes happened in Adrasan and Kumluca (Antalya) in June 2016 are obtained. The remotely sensed image bands are first merged with the Erdas 2014 program and fusion is applied. Then, by the help of eCognition program, segmentation process is applied by using Normalized Difference Vegetative Index (NDVI), Soil-Adjusted Vegetation Index (SAVI), Global Environmental Monitoring Index (GEMI), Vegetation Index (VI), Ratio Vegetation Index (RVI), and Ashburn Vegetation Index (AVI) indexes with parameters of Scale:120, Shape:0,4, Compactness:0,6. The shape files obtained after the segmentation are cropped by the help of ArcMap program and training and test data are formed. These files are classified according to Support Vector Machines (SVM) and Rotation Forest (ROF) advanced classification techniques by the help of Weka program. Finally, accuracy analysis of the obtained results of the classifications has performed. According to results of the accuracy analysis, Kappa is 0,86 and total accuracy is 0,93 for ROF, Kappa is 0,9 and total accuracy is 0,95 for SVM. When the results are compared, it has seen that SVM seems to be a more successful method than ROF.
\end{abstract}

Keywords: burned forest areas, object-based classification, rotation forest, support vector machines, Worldview-2

\section{GİRIŞ}

Uydu teknolojilerinde yaşanan olumlu gelişmeler sayesinde yüksek konumsal çözünürlüğe sahip uzaktan algılanmış görüntülerde çözünürlük ve dolayısıyla ayrıntı artmıştır. Bundan dolayı geleneksel piksel tabanlı sınıflandırma yerine nesne tabanlı sınıflandırmanın kullanımı önem kazanmıştır (Çölkesen vd., 2015). Uzaktan algılanmış uydu görüntüsündeki piksellerin daha önceden bilinen arazi örtüsüyle eşleştirilmesi görüntü sınıflandırma olarak adlandırılır. Yapılan sınıflandırmada kullanılan algoritmalara görüntü sınıflandırıcıları adı verilir (Mather, 1987). Uzaktan algılanmış görüntülerden görüntü sınıflandırıcıları kullanılarak arazi örtüsü/kullanımı bilgilerinin elde edilmesi uzaktan algılamaya olan ilgiyi arttırmıştır. Bu ilgi sonucu daha yüksek doğruluklu sınıflandırıcı bulmak için yapılan çalışmalar devam etmekte olup Destek Vektör Makinaları (DVM) ve Rotasyon Orman (ROR) gibi sınıflandırıcılar günümüzde uzaktan algılama ile uğraşanların dikkatini çekmiştir (Guo vd., 2018; Huang vd., 2002; Liu ve Huang, 2008; Rodriguez vd., 2006).

Destek Vektör Makinalarının temelleri kuramsal olarak istatistiksel öğrenmeye dayanmaktadır (Corinna ve Vladimir). Ses tanıma, yüz tanıma, imza tanıma, karakter tanıma ve el yazısı tanıma gibi birçok değişik uygulama alanında DVM kullanılmıştır (Corinna ve Vladimir; Joachims, 1998). DVM son yıllarda uzaktan algılanmış görüntülerin sınıflandırılmasında da sık bir biçimde kullanılmaktadır (Gürcan vd., 2016; Huang vd., 2002; Jimenez-Munoz vd., 
2009; Myint vd., 2011). DVM'ler de Parametrik Olmayan Sınıflandırıcılar ve Yapay Sinir Ağları gibi herkesçe bilinen bir hâle gelmiştir (Foody ve Mathur, 2004a, b). DVM, Doğrusal olarak ayrılabilen verileri sınıflandırmak için doğrusal sınıflandırıcılar kullanarak gruplandırma işlemini gerçekleştirir. Bu işlemi farklı sınıflandırıcılarla yapmakta mümkündür. Destek Vektör Makinalarının aslında kullanıldığı alan uzaktan algılanmış görüntüler gibi birbirinden doğrusal olarak ayrılamayan karmaşık verilerdir. Bu işlemi yaparken DVM, giriş uzayındaki eğitim verilerini kernel (çekirdek) fonksiyonu kullanarak daha yüksek boyutta bir özellik uzayına doğrusal olmayan şekilde yansıtır. DVM'de veri noktalarıyla karar sınırı arasındaki mesafenin maksimum olması istenir. Bunun sebebi deneysel olarak yapılması muhtemel olan yanlış sınıflandırmaları minimum seviyeye indirmektir (Mashao, 2003). Uygulamada, bu ölçüt hem sınıflandırıcının karmaşıklığını hem de aykırı noktaların yanlış sınıflandırılmasının seviyesini içeren bir maliyet etmeninin minimize edilmesiyle yumuşatılır. Bu, "C" olarak bilinen hata parametresi tarafindan, etmenler arasındaki çapraz doğrulama prosedürleriyle ayarlanan bir değer ile yönetilir (Mashao, 2003). Girdi uzayındaki verileri, özellik alanına yansıtmak için kullanılan fonksiyonlar çekirdek (kernel makinaları) olarak isimlendirilir. Bunlardan en yaygın kullanılanlar Polinominal ve Gaussian RBF (daha bilindik şekilde radyal temel fonksiyonu) fonksiyonlarıdır. Her fonksiyon için sınıflandırma işlemine başlamadan önce belirlenmesi gereken bir parametre vardır. Bu parametreler çapraz doğrulama işlemi ile belirlenir. DVM'ler yapıları gereği ikili sınıflandırıcılar olarak bilinir fakat son zamanlarda uzaktan algılamada yapılan çalışmalar göstermiştir ki çok sınıflı sınıflandırıcılarda da başarılı sonuçlar elde edilmiştir (Guo vd., 2018; Liu vd., 2017). Birebir ve bire hepsi en yaygın tercih edilen tekniklerdir (Anthony vd., 2007).

Tek sınıflandırıcı ile mukayese edildiğinde çoklu sınıflandırıcılar daha üstün doğruluk gösterirler. AdaBoost'un sınıflandırıcı topluluk modelleri arasında en iyi hazır sınıflandırıcı olduğunu yapılan çalışma göstermiştir (Breiman, 1998). Topluluk sınıflandırıcılarının birbirinden bağımsız olarak rastgeleleştirme keşiflerini kullanarak sınıflandırmanın yapıldığı Torbalama, AdaBoost'a yakın bir rakiptir (Breiman, 1996, 2001). AdaBoost'a göre torbalamanın daha yüksek doğruluk verdiği bulunmuştur fakat her iki yönteminde yeterli doğruluğu olmadığ1 düşünülmektedir (Bauer ve Kohavi, 1999). Rastgele Orman; rastgele karar ormanları, regresyon ve sınıflandırma için çok sayıda karar ağacının inşa edilmesi veya ortalama tahminin üretilmesiyle çalışan bir topluluk öğrenme yöntemidir (Barandiaran, 1998; Ho, 1995). Her düğümde rastgele özellik seçerek ek çeşitlilik ortaya çıkarmaktadır. Ağaç oluşumunda ise her düğümdeki optimum özellik ilgili algoritmanın bir değişkeni olan rastgele seçilmiş özellikleri arasından seçilir. Rotasyon Ormanın çalışma mantığı Rastgele Ormana benzer (Rodriguez vd., 2006). Rotasyon Ormanında yer alan her ağaç döndürülmüş nitelik bölgesinde tüm data setleri üstünde eğitilir. Ağaç öğrenme algoritmalarının eksenlerindeki minik dönme hareketi çok değişik bir ağaç oluşmasına sebep olabilir. Rodriguez ve arkadaşları yaptıkları çalışma sonucu Rotasyon Ormanın AdaBoost, torbalama ve Rastgele Ormana göre daha yüksek doğruluğa sahip olduğu sonucuna varmışlar ve Rotasyon Ormanı tercih etmişlerdir (Rodriguez vd., 2006). Rotasyon Orman ve AdaBoost'a ait Kappa ve hata matrisi analizi incelendiğinde ROR'un daha hassas sınıflandırıcılar kullandığı ve bunun da torbalama algoritmasından farklı olduğu ortaya çıkarılmıştır (Kuncheva ve Rodríguez, 2007).

\section{2. ÇALIŞMA ALANI}

Çalışma alanı olarak TOD raporlarına göre Türkiye'nin birinci derece orman yangını riski olan Antalya bölgesi belirlenmiştir (http-1). Antalya'nın Adrasan ve Kumluca bölgelerinde 2016 yılında meydana gelen yangın alanı seçiliştir. Bu yangın sonucunda yüzlerce dekar alan yanmış, onlarca ev kül olmuş ve yüzlerce hayvan telef olmuştur. Bu yangın bölgesine ait Google Earth görüntüsü Şekil 1'de verilmiştir.

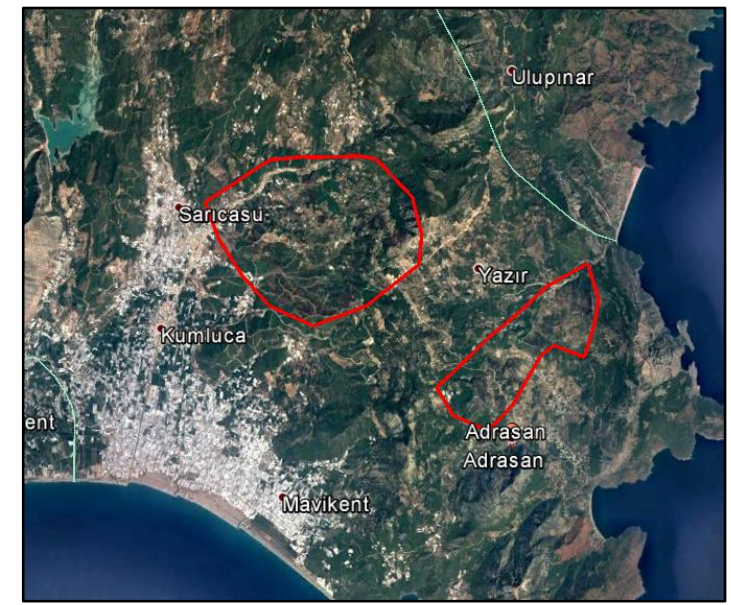

Şekil 1. Çalışma alanına ait Google Earth görüntüsü. 


\section{MATERYAL VE YÖNTEM}

\subsection{Veri Seti}

Çalışmada, yanmış alanların tespit edilmesi için Worldview-2 uydusuna ait 8 spektral banda sahip uzaktan algılanmış görüntü kullanılmıştır. Worldview-2 uydusu, 2009 yılında uzaya firlatılmış olup 8 multispektral banda sahip ilk gözlem uydusudur. Uydu, yersel olarak 0,46 metre pankromatik ve 1,84 metre multispektral çözünürlüğe sahiptir. 770 km irtifaya konumlandırılmış olan uydu, 1.1 günde tekrar ziyaret etme ve en fazla her gün 975.000 km²'lik bölgenin görüntüsünü çekebilme yeteneğine sahiptir.

\subsection{Yöntem}

Worldview-2 uydusundan elde edilen uzaktan algılanmış görüntünün, band parlaklık değerleri ve band parlaklık değerlerine matematiksel işlem uygulayarak elde edilen bitki örtüsü indis değerleri kullanılarak nesne tabanlı sınıflandırma işlemi yapılmıştır.

Bu çalışmada Worldview-2 uydu görüntüsünün nesne tabanlı yaklaşımla sınıflandırılmasında aşağıdaki indisler kullanılmıştır.

\subsubsection{Normalize Edilmiş Farksal Bitki Örtüsü İndisi (NDVI)}

Bu indis, bitki örtüsünün güçlü bir şekilde yansıdığı yakın kızılötesinin ve bitki örtüsünün emildiği kırmızı 1şığın arasındaki farkı hesaplayarak vejetasyonu ölçmektedir (Formül 1). NDVI değeri \pm 1 'dir. Örnek olarak, NDVI değeri negatif hesaplandıysa o bölgenin suyla kaplı olması muhtemeldir. Ya da bu değer pozitif ise bu bölgenin yeşil yapraklı bitkilerle kaplı olma olasılığı yüksektir. Eğer değer 0 ise bu alanın kentsel alan olduğu söylenebilir.

$$
\mathrm{NDVI}=\frac{(\mathrm{NIR}-\mathrm{Red})}{(\mathrm{NIR}+\mathrm{Red})} \quad(\text { Tucker, 1979) }
$$

Çalışılan bölge için hesaplanmış Normalize Edilmiş Farksal Bitki Örtüsü İndisine ait ekran görüntüsü Şekil 2'de verilmiştir.

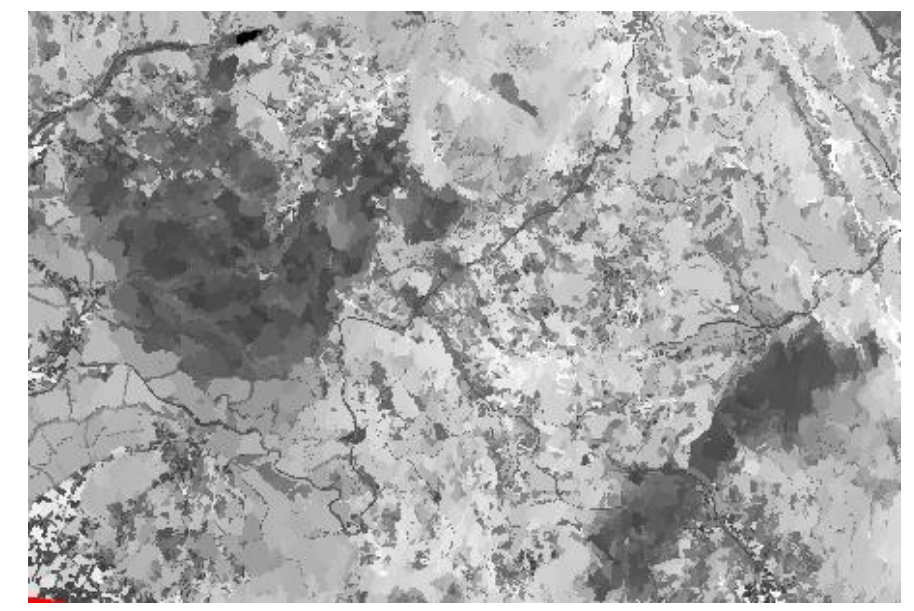

Şekil 2. Normalize Edilmiş Farksal Bitki Örtüsü İndisine ait ekran görüntüsü.

\subsubsection{Bitki Örtüsü Oran İndisi (RVI)}

Bitki Örtüsü Oran İndisi, bitki örtüsünün güçlü bir şekilde yansıttığı yakın kızılötesi bandının, vejetasyonun emdiği kırmızı banda oranıdır (Formül 2).

$$
\mathrm{RVI}=\frac{\mathrm{NIR}}{\operatorname{Red}} \quad \text { Blackburn, 1998) }
$$

Bitki Örtüsü Oran İndisine ait ekran görüntüsü Şekil 3’te verilmiştir. 


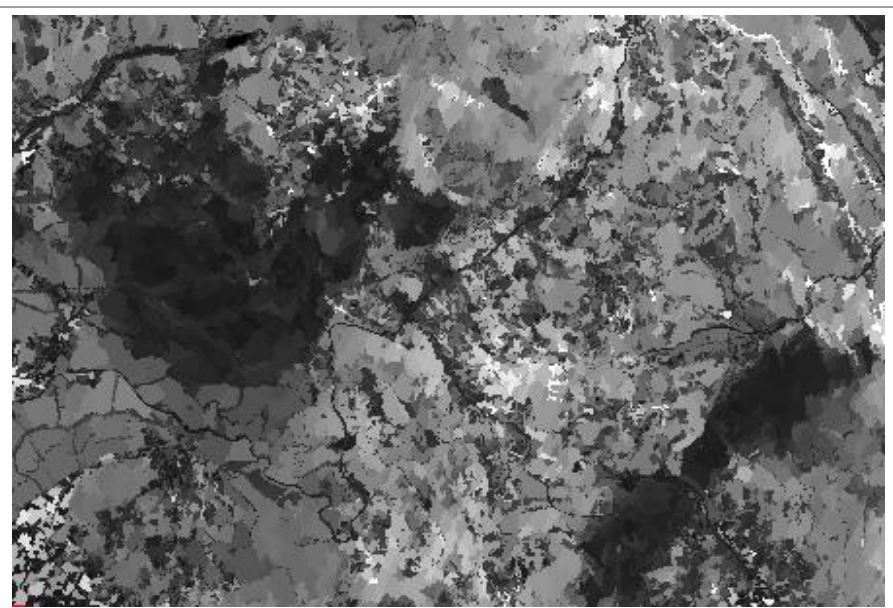

Şekil 3. Bitki Örtüsü Oran İndisine ait ekran görüntüsü.

\subsubsection{Toprak Ayarlı Bitki Örtüsü İndisi (SAVI)}

Vejetasyon oranının \%40’ın altında olduğunda topraktan yansımanın etkisini azaltmak için NDVI'nın üzerinde değişiklik yapılması sonucu elde edilen bir indistir (Formül 3a, 3b).

Toprak Ayarlı Bitki Örtüsü İndisi, Normalize Edilmiş Farksal Bitki Örtüsü İndisine benzer şekilde inşa edilmiştir. Fakat NDVI formülüne "L" olarak sembolize edilen "toprak parlaklığı düzeltme faktörü" eklenmiştir. Formüldeki "L" değeri yerine "0" yazıldığında SAVI denklemi NDVI’a eşit olmaktadır.

$$
\begin{aligned}
& \text { SAVI }=(1+\mathrm{L}) \frac{(\mathrm{NIR}-\mathrm{Red})}{(\mathrm{NIR}+\mathrm{Red}+\mathrm{L})} \\
& \text { SAVI }=(1+0,5) \frac{(\mathrm{NIR}-\mathrm{Red})}{(\mathrm{NIR}+\mathrm{Red}+0,5)}(\text { Huete, 1988) }
\end{aligned}
$$

Toprak Ayarlı Bitki Örtüsü İndisine ait ekran görüntüsü Şekil 4’te verilmiştir.

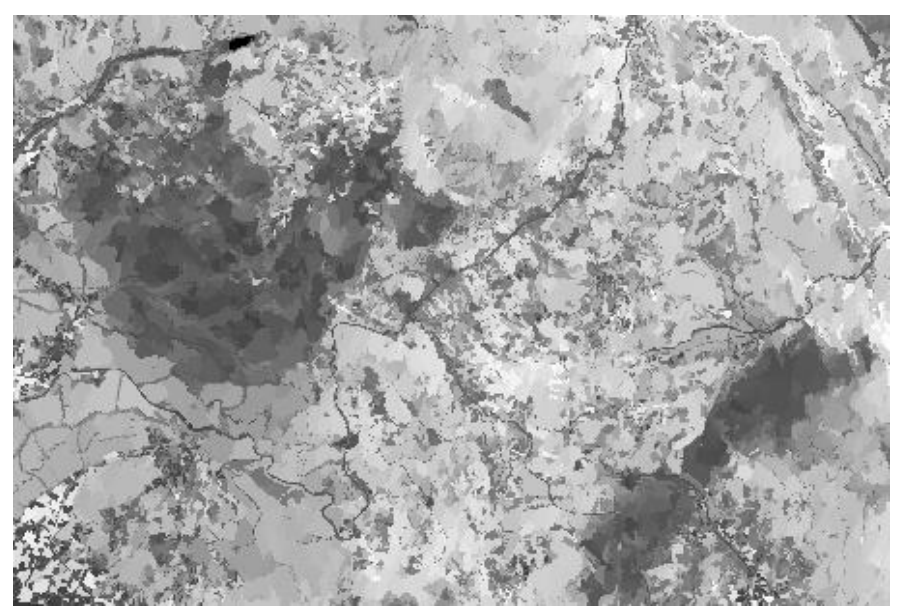

Şekil 4. Toprak Ayarlı Bitki Örtüsü İndisine ait ekran görüntüsü.

\subsubsection{Küresel Çevre İzleme İndisi (GEMI)}

Küresel Çevre İzleme İndisi, atmosferin tesirinin izafi etkisini minimize edecek biçimde yapılandırılmış yeni bir indisin türetilmesi sonucu oluşturulmuştur.

$$
\text { GEMI }=\gamma(1-0,25 \gamma)-\frac{(\operatorname{Red}-0,125)}{(1-\text { Red })}
$$




$$
\gamma=\frac{\left[2 \mathrm{x}\left(\mathrm{NIR}^{2}-\mathrm{Red}^{2}\right)+(1,5 \mathrm{xNIR})+(0,5 \mathrm{xRed})\right]}{(\mathrm{NIR}+\mathrm{Red}+0,5)} \quad \text { (Pinty ve Verstraete, 1992) }
$$

Küresel Çevre İzleme İndisine ait ekran görüntüsü Şekil 5’te verilmiştir.

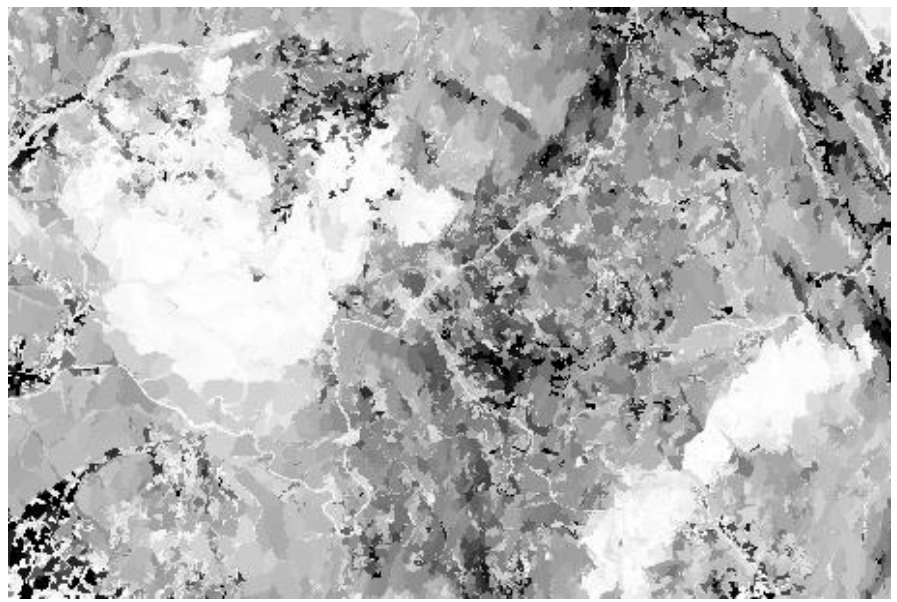

Şekil 5. Küresel Çevre İzleme İndisine ait ekran görüntüsü.

\subsubsection{Ashburn Bitki İndisi (AVI)}

Aralıklı bitki örtüsüne hassasiyeti olan bu indis, \%15-20 vejetasyonun çıplak olduğu topraktan erken periyoda ait bitki örtüsünü ayırt edebilir.

Ashburn Bitki İndisi atmosferin zayıflama tesirlerini Normalize Edilmiş Farksal Bitki Örtüsü İndisinden daha fazla minimize eder (Formül 5).

AVI $=2 \times$ NIR - Red (Ashburn, 1979)

Ashburn Bitki İndisine ait ekran görüntüsü Şekil 6'da verilmiştir.

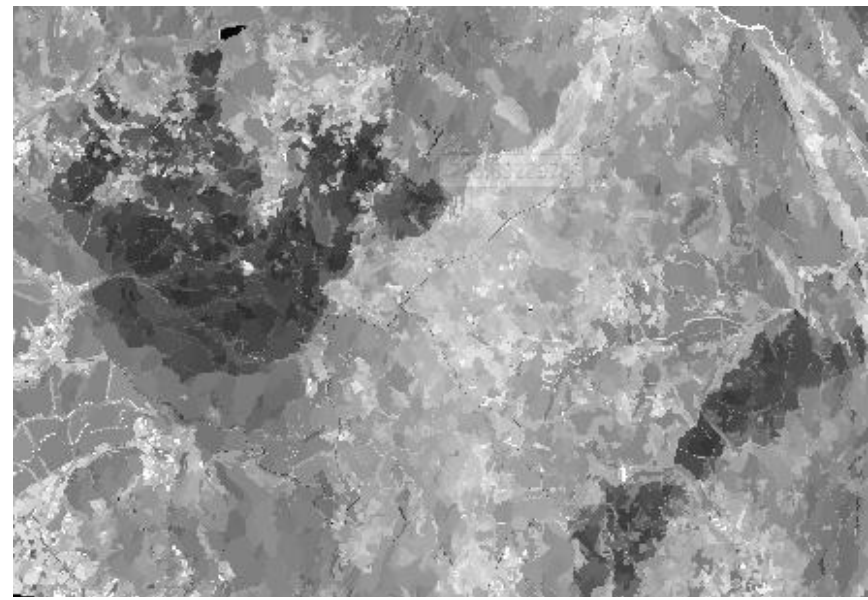

Şekil 6. Ashburn Bitki İndisine ait ekran görüntüsü.

\subsubsection{Bitki Örtüsü İndisi (VI)}

VI, vejetasyonun özelliklerinin faydasını arttırmak için ve karasal fotosentez faaliyeti ile kanopi konstrüktif çeşitliliklerinin güvenilir zamansal ve mekânsal mukayesesini temin etmek maksadıyla geliştirilmiş iki veya daha çok bandın spektral bir transformasyonudur (Formül 6). 


$$
\mathrm{VI}=\frac{(\text { Green }- \text { Red })}{(\text { Green }+ \text { Red })} \quad(\text { Gitelson vd., 2002) }
$$

Bitki Örtüsü İndisine ait ekran görüntüsü Şekil 7'de verilmiştir.

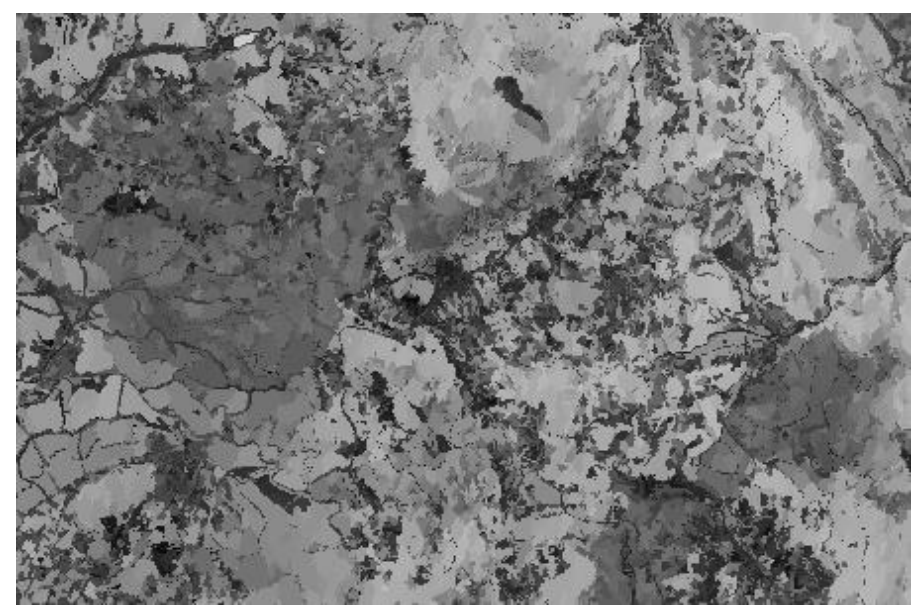

Şekil 7. Bitki Örtüsü İndisine ait ekran görüntüsü.

\section{UYGULAMA}

Çalışma, Şekil 8'de gösterilen akış diyagramında olduğu gibi 6 basamaktan oluşmaktadır.

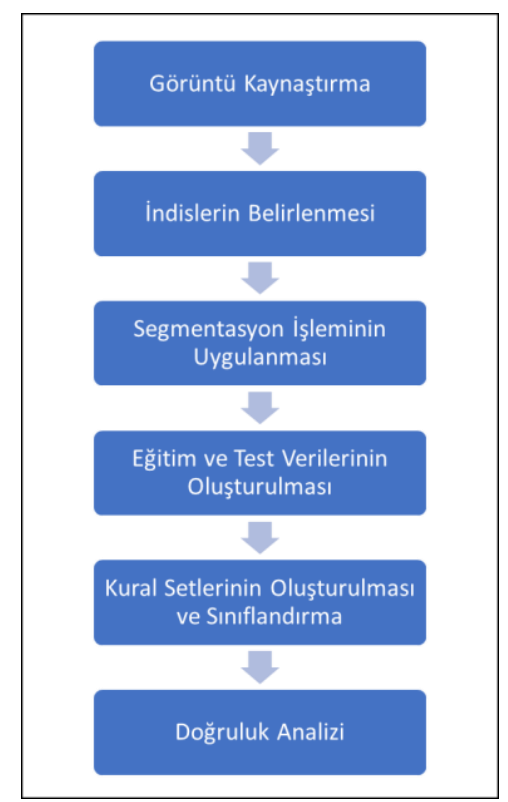

Şekil 8. Çalışmaya ait akış diyagramı.

İlk işlem basamağı, görüntünün kaynaştırılması ya da diğer bir ifadeyle keskinleştirilmesi işlemidir. Bu işlem için Erdas 2014 paket programında var olan "HPF Resolution Merge" fonksiyonu kullanılmış ve spektral bantlarla pankromatik bandın kaynaştırılması yapılmıştır.

Özdemir (2017), Worldview-2 uydusuna ait görüntüye önce keskinleştirme işlemi uygulanmış daha sonra da oluşan yeni görüntüden nesne tabanlı sınıflandırma yapılmıştır. Sonuçlar göstermiştir ki keskinleştirilmiş uydu görüntüsünden temin edilen nesne tabanlı sınıflandırmadan yeterli doğruluk elde edilebilmiştir (Özdemir, 2017).

HPF ile keskinleştirme işlemi, yüksek çözünürlüğe sahip pankromatik görüntünün daha düşük çözünürlüğe sahip multispektral görüntüyle birleştirilmesi olarak açıklanır ve bu da mükemmele yakın ayrıntılar elde edilmesini sağlar. Yüksek Geçiş Filtresi (HPF) kullanılarak yüksek çözünürlüklü datalarda bir kıvrım oluşturulur ardından bu veri multispektral datalarla kaynaştırılır [http-2].

Çalışmanın sonraki basamağında literatür taranmış ve bu tarz çalışmalarda tercih edilenlerden optimum fayda sağlayacak NDVI, VI, SAVI, RVI, AVI ve GEMI indisleri belirlenmiştir (Ashburn, 1979; Blackburn, 1998; Gitelson 
vd., 2002; Huete, 1988; Pinty ve Verstraete, 1992; Tucker, 1979). Bu indisleri belirlemek amaciyla eCognition Developer (V.9.0) programı kullanılmış, yanmış orman bölgelerinin tek tek yansımaları kontrol edilmiş ve optimum değer verenler tercih edilmiştir.

Sürecin üçüncü aşamasında, eCognition programında görüntü bölütleme işlemi yapılmıştır. Bu işlem basamağı uygulanırken eCognition'daki "Subset Selection” yeteneği kullanılmıştır. Böylelikle uydu görüntüsünün küçük bir kısmında çalışma yapılarak deneme yanılma yöntemiyle indisler belirlenmiştir. Küçük alanda çalışmanın avantajı, değişkenlerin belirlenmesi için tüm görüntüde çalışarak harcanacak olan zamanın minimize edilmesidir. Kısa sürede elde edilen değişkenlere ait değerler Çizelge 1'de verilmiştir.

Çizelge 1. Segmentasyon parametre değerleri.

\begin{tabular}{|l|l|l|l|}
\hline Uydunun Adı & Ölçek Parametresi & Şekil Parametresi & $\begin{array}{l}\text { Yoğunluk } \\
\text { Parametresi }\end{array}$ \\
\hline Worldview-2 & 120 & 0.3 & 0.7 \\
\hline
\end{tabular}

Belirlenen indislerle ve değişkenlerle görüntü bölütleme işlemi yapılmış, piksellerden nesneler oluşturulmuştur. Temin edilen nesneler şekil dosyası olarak kaydedilmiştir.

Ardından test ve eğitim verileri hazırlanmıştır. Bu amaçla Kumluca bölgesi eğitim verisinin ve Adrasan bölgesi test verisinin içinde olacak şekilde görüntü ArcMap programı yardımıyla ikiye bölünmüştür. Hazırlanan verilerle Weka programında DVM ve ROR yöntemleri kullanılarak sınıflandırma yapılmıştır. Sınıflandırma sonucu elde edilmiş verilere ait görüntüler Şekil 9'da verilmiştir. Sınıflandırmaya ait veriler görselleştirilerek gözle sınıflandırmanın doğruluğu kontrol edilmiştir.

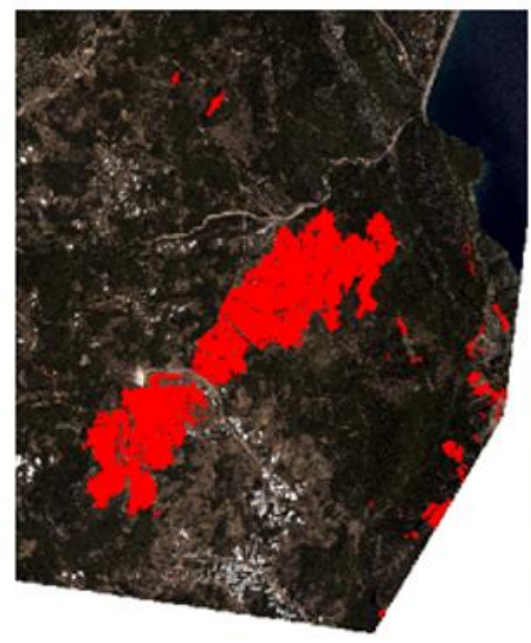

(a)

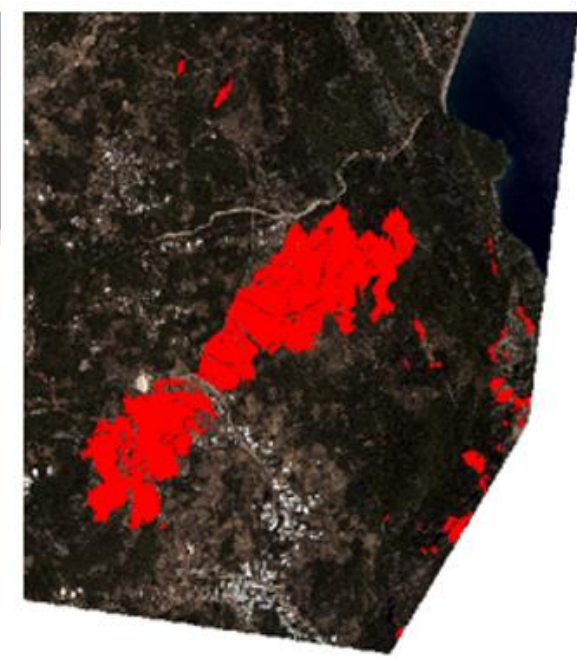

(b)

Şekil 9. (a) DVM ve (b) ROR verilerine ait görüntüler.

Son olarak kontrol noktaları oluşturulmuş ve doğruluk analizi yapılmıştır. Çalışmada yanmış alan ve yanmamış alan olarak iki sınıf oluşturulmuştur. İkili sınıflandırmada kaç adet kontrol noktasına ihtiyaç olduğunu bulmak için "İki Terimli Olasılık Teorisi” kullanılmıştır (Aronoff, 1982; Lucas vd., 1994). Bu teoriye göre;

$\mathrm{N}=\mathrm{Z}^{2} \cdot \mathrm{p} \cdot \mathrm{q} / \mathrm{E}^{2}$

$\mathrm{N}=2^{2} \cdot(85.15) / 4^{2}$

$\mathrm{N}=319$

Yapılan çalışmada doğruluk beklentisi olarak \%85 ve \%4'lük kabul edilebilir hata belirlenmiştir. Bu değerler formüle tatbik edildiğinde en az 319 kontrol noktasına gereksinim duyulduğu hesaplanmıştır. Çalışma için 350 tane kontrol noktası üretilmiştir. Bu noktaların 250 adedi yanmış alana denk gelecek şekilde üretilmiştir. Üretilen kontrol noktalarının ekran görüntüsü Şekil 10’ da verilmiştir. 




Şekil 10. Üretilen noktalara ait ekran görüntüsü.

\section{SONUÇ VE ÖNERILER}

Doğruluk analizi için DVM ve ROR'a ait sonuç verileri ile hata matrisi oluşturulmuştur (Çizelge 2).

Çizelge 1. Hata matrisi.

\begin{tabular}{|c|c|c|c|c|}
\hline Yöntem & Sinıfin Adı & Yanmamış Alan & Yanmış Alan & Toplam \\
\hline \multirow{3}{*}{ DVM } & Yanmamış Alan & 191 & 8 & 199 \\
\hline & Yanmış Alan & 10 & 141 & 151 \\
\hline & Toplam & 201 & 149 & \\
\hline \multirow{3}{*}{ ROR } & Yanmamış Alan & 196 & 3 & 199 \\
\hline & Yanmış Alan & 20 & 131 & 151 \\
\hline & Toplam & 216 & 134 & \\
\hline
\end{tabular}

Oluşturulan hata matrisine göre kullanıcı ve üretici doğruluğu, ihmal ve komisyon hataları ve Kappa analizi yapılmıştır (Çizelge 3).

Çizelge 2. Doğruluk analizi sonuçları.

\begin{tabular}{|c|c|c|c|c|c|c|}
\hline $\begin{array}{c}\text { Sinıflandırma } \\
\text { Yöntemi }\end{array}$ & $\begin{array}{c}\text { Kullanıcı } \\
\text { Doğruluğu }\end{array}$ & $\begin{array}{c}\text { Üretici } \\
\text { Doğruluğu }\end{array}$ & $\begin{array}{c}\text { İhmal } \\
\text { Hataları }\end{array}$ & $\begin{array}{c}\text { Komisyon } \\
\text { Hataları }\end{array}$ & Kappa & $\begin{array}{c}\text { Toplam } \\
\text { Doğruluk }\end{array}$ \\
\hline DVM & 93.38 & 94.63 & 6.71 & 6.62 & 0.90 & 0.95 \\
\hline ROR & 86.75 & 97.76 & 14.93 & 13.25 & 0.86 & 0.93 \\
\hline
\end{tabular}

Uydu sensörlerinde yaşanan olumlu gelişmeler sonucunda daha yüksek çözünürlüklü yani daha ayrıntılı görüntüler elde edilmeye başlanmıştır. Bu da görüntülerin sınıflandırılmasında karşılaşılan problemlerin çözümünü daha zor hâle getirmiştir (Çölkesen vd., 2015). Yersel çözünürlüğün artması yanmış orman bölgelerini ifade eden ve spektral açıdan birbirine benzeyen tutumlar gösteren data setlerini meydana getirmiştir. Bu setleri piksel tabanlı tek tek sınıflandırmak hem zaman kaybına hem de güvenilirlik açısından düşük doğruluğa sebep olmaktadır. Bunun yerine, yapılan çalışmalarda obje tabanlı sınıflandırma uygulanarak belirtilen negatif faktörler arındırılmış olmaktadır. Bunun yanı sıra nesne tabanlı sinıflandırmalarda ROR ve DVM gibi ileri sinıflandırma tekniklerinin kullanılmasıyla veri madenciliği kullanımı da uzaktan algılamada uygulanan yöntemler arasında yer edinmiştir.

Çalışma sonucunda elde edilen veriler incelendiğinde yapılan sınıflandırmada yanmış alanların neredeyse tamamı otomatik olarak çıkartılmıştır. Hem Destek Vektör Makinaları hem de Rotasyon Orman ile yapılan sınıflandırma sonucu elde edilen verilere ait doğruluk analizi incelendiğinde her iki yönteminde yanmış alanların belirlenmesi için uygun olduğu tespit edilmiştir. Destek Vektör Makinaları için; toplam doğruluk 0.95 ve Kappa 0.9, Rotasyon Orman 
için ise toplam doğruluk 0.93 ve Kappa 0.86 'dır. Bu iki sınıflandırılma mukayese edildiğinde Destek Vektör Makinalarının Rotasyon Ormana göre daha güvenilir olduğu sonucu ortaya çıkarılmıştır.

Çalışmada kullanılan Worldveiw-2 uydusuna keskinleştirme işlemi yapılmıştır. Başka bir çalışmada keskinleştirmenin sınıflandırmaya olan etkisi incelebilir.

Literatür araştırıldığında bu tarz çalışmalarda NBR (Normalized Burn Ratio-Normalize Edilmiş Yanma Şiddeti) indisinin çok sık kullanıldığı ve yüksek doğruluklu sonuçlar elde edildiği gözlemlenmiştir. Worldview-2 uydusuna ait NBR indisi bulunmamasından dolayı bu çalışmada bahsi geçen indise yer verilmemiştir. İleriki dönemlerde yapılacak olan çalışmalarda bu indis belirlenerek daha yüksek doğruluklu bir sonuç elde edileceği tahmin edilmektedir.

Çalışma sonucu elde edilen görüntüler incelendiğinde 2016 yılında meydana gelen yanmış bölgeler dışında başka alanlarında yanmış alan olarak sınıflandırıldığı tespit edilmiştir. Çalışılan bölgenin birinci derece yangın riski taşıyan alan olması sebebi ile bazı yanlış sınıflandırmaların eski tarihli yanmış alan olabileceği değerlendirilmektedir. Çalışmanın amacının 2016 yılındaki yangın sonucu oluşan yanmış alanların çıkarılması olması sebebiyle diğer bölgeler yanlış sınıflandırma olarak kabul edilmiştir. Bu da yapılan çalışmanın doğruluğunu olumsuz yönde etkilemektedir.

\section{KAYNAKLAR}

Anthony, G., Greg, H. ve Tshilidzi, M., 2007. Classification of images using support vector machines. arXiv preprint arXiv:0709.3967.

Aronoff, S., 1982. Classification accuracy: a user approach. Photogrammetric Engineering and Remote Sensing, 48(8): 1299-1307.

Ashburn, P., 1979. The vegetative index number and crop identification.

Barandiaran, I., 1998. The random subspace method for constructing decision forests. IEEE transactions on pattern analysis and machine intelligence, 20(8).

Bauer, E. ve Kohavi, R., 1999. An empirical comparison of voting classification algorithms: Bagging, boosting, and variants. Machine learning, 36(1-2): 105-139.

Blackburn, G.A., 1998. Spectral indices for estimating photosynthetic pigment concentrations: A test using senescent tree leaves. International Journal of Remote Sensing, 19(4): 657-675.

Breiman, L., 1996. Bagging predictors. Machine learning, 24(2): 123-140.

Breiman, L., 1998. Arcing classifier (with discussion and a rejoinder by the author). The annals of statistics, 26(3): 801-849.

Breiman, L., 2001. Random forests. Machine learning, 45(1): 5-32.

Corinna, C. ve Vladimir, V., Support-Vector Networks. Machine Leaming, 20, 273-297 (1995) 1995 Kluwer Academic Publishers, Boston. Manufactured in The Netherlands.

Çölkesen, İ., Yomralığlu, T. ve Kavzoğlu, T., 2015. Obje Tabanlı Sınıflandırmada Bölgeleme Esasına Dayalı Ölçek Parametresi Tespiti: WorldView-2 Uydu Görüntüsü Örneği.

Foody, G.M. ve Mathur, A., 2004a. A relative evaluation of multiclass image classification by support vector machines. IEEE Transactions on Geoscience and Remote Sensing, 42(6): 1335-1343.

Foody, G.M. ve Mathur, A., 2004b. Toward intelligent training of supervised image classifications: directing training data acquisition for SVM classification. Remote Sensing of Environment, 93(1-2): 107-117.

Gitelson, A.A., Kaufman, Y.J., Stark, R. ve Rundquist, D., 2002. Novel algorithms for remote estimation of vegetation fraction. Remote sensing of Environment, 80(1): 76-87.

Guo, Y., Jia, X. ve Paull, D., 2018. Effective Sequential Classifier Training for SVM-Based Multitemporal Remote Sensing Image Classification. IEEE Transactions on Image Processing.

Gürcan, İ., Teke, M. ve Leloğlu, U.M., 2016. Land use/land cover classification for Göktürk-2 satellite. Signal Processing and Communication Application Conference (SIU), 2016 24th, syf: 2097-2100.

Ho, T.K., 1995. Random decision forests. Document analysis and recognition, 1995., proceedings of the third international conference on, 1 (syf: 278-282.

Huang, C., Davis, L.S. ve Townshend, J.R.G., 2002. An assessment of support vector machines for land cover classification. International Journal of Remote Sensing, 23(4): 725-749.

Huete, A.R., 1988. A soil-adjusted vegetation index (SAVI). Remote Sensing of Environment, 25(3): 295-309.

Jimenez-Munoz, J.C., Sobrino, J.A., Plaza, A., Guanter, L., Moreno, J. ve Martinez, P., 2009. Comparison Between Fractional Vegetation Cover Retrievals from Vegetation Indices and Spectral Mixture Analysis: Case Study of PROBA/CHRIS Data Over an Agricultural Area. Sensors (Basel), 9(2): 768-793.

Joachims, T., 1998. Text categorization with support vector machines: Learning with many relevant features. European conference on machine learning, syf: 137-142.

Kuncheva, L.I. ve Rodríguez, J.J., 2007. An experimental study on rotation forest ensembles. International workshop on multiple classifier systems, syf: 459-468.

Liu, K.-H. ve Huang, D.-S., 2008. Cancer classification using rotation forest. Computers in biology and medicine, 38(5): 601-610. 
Liu, P., Choo, K.-K.R., Wang, L. ve Huang, F., 2017. SVM or deep learning? A comparative study on remote sensing image classification. Soft Computing, 21(23): 7053-7065.

Lucas, I., Frans, J. ve Wel, V., 1994. Accuracy assessmentof satellite derived land2over data: A review. Photog ramm etric Engineering \& Rem ote Sensing, 60(4): 410-432.

Mashao, D.J., 2003. Comparing SVM and GMM on parametric feature-sets. Proceedings of the 14th Annual Symposium of the Pattern Recognition Association of South Africa.

Mather, P.M., 1987. Computer processing of remotely-sensed images-An introduction.

Myint, S.W., Gober, P., Brazel, A., Grossman-Clarke, S. ve Weng, Q., 2011. Per-pixel vs. object-based classification of urban land cover extraction using high spatial resolution imagery. Remote Sensing of Environment, 115(5): 1145-1161.

Özdemir, M., 2017. Görüntü Keskinleştirme Yöntemlerinin Nesne-Yönelimli Sınıflandırma Açısından Değerlendirilmesi.

Pinty, B. ve Verstraete, M., 1992. GEMI: a non-linear index to monitor global vegetation from satellites. Vegetatio, 101(1): 15-20.

Rodriguez, J.J., Kuncheva, L.I. ve Alonso, C.J., 2006. Rotation forest: A new classifier ensemble method. IEEE transactions on pattern analysis and machine intelligence, 28(10): 1619-1630.

Tucker, C.J., 1979. Red and photographic infrared linear combinations for monitoring vegetation. Remote Sensing of Environment, 8(2): 127-150.

Internet kaynakları:

http-1 https://www.ogm.gov.tr/ekutuphane/sayfalar/Istatistikler.aspx (02.03.2018)

http-2 ftp://jetty.ecn.purdue.edu/jshan/ERDAS_Library (26.04.2018) 